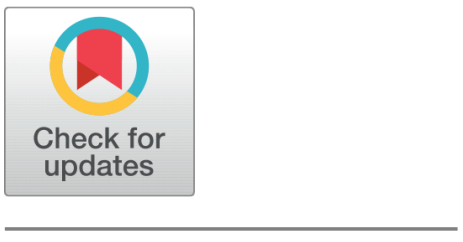

open ACCESS

Received: 01.02.2021

Accepted: 12.04.2021

Published: 27.07.2021

Citation: Linas-Laguda M (2021) Doing Math and Other Things: A Peek at Multiple Intelligences and Numeracy Level. Indian Journal of Science and Technology 14(25): 2137-2144. https://doi.org/ 10.17485/IJST/v14i25.194

* Corresponding author.

fernantupas@yahoo.com

Funding: None

Competing Interests: None

Copyright: (c) 2021 Linas-Laguda. This is an open access article distributed under the terms of the Creative Commons Attribution License, which permits unrestricted use, distribution, and reproduction in any medium, provided the original author and source are credited.

Published By Indian Society for Education and Environment (iSee)

ISSN

Print: 0974-6846

Electronic: 0974-5645

\section{Doing Math and Other Things: A Peek at Multiple Intelligences and Numeracy Level}

\author{
Marilyn Linas-Laguda ${ }^{1 *}$ \\ 1 Faculty, Teacher Education Department, Northern Iloilo Polytechnic State College \\ Concepcion Campus, Concepcion, Iloilo, Philippines
}

\section{Abstract}

Objectives : To determine the relationships of Multiple Intelligences of College Freshmen to their Mathematics Performance among 68 first-year College students taking up Bachelor of Secondary Education major in Mathematics of Northern Iloilo Polytechnic State College (NIPSC). Methods: The researcher used descriptive-correlational design in this study. A survey utilizing the researcher-made checklist determined the relationship of multiple intelligences as the main variables used in the research. Findings/application: The results showed more females enrolled in the programs than males in the academic year 2015-2016. Most of these students were from different barangays in northern Iloilo. Out of the $9 \mathrm{Ml}$, most of the students possessed existentialist intelligence because they wanted to become teachers in the future. However, the majority of these 68 respondents failed the entrance examination. But out of four campuses, Barotac Viejo Campus students have a higher performance in Mathematic class. But no significant difference between sex and MI. Furthermore, the results also exposed that if students excelled in Mathematics in high school, they were too good in college. Also, most of the respondents were good in linguistic intelligence. During problem-solving activities, most of them can read, analyze, and comprehend verbal instructions. To enhance the performance of students enrolled in BSEd major Mathematics in four campuses creates a plan to help teachers in junior high schools and senior high schools like teaching strategy and interactive approaches. Also, remedial classes are implemented for those who are not performing well in college.

Keywords: Northern Iloilo Polytechnic State College; Bachelor of Secondary Education (Mathematics); FirstYear; Performance; Multiple intelligences

\section{Introduction}

For the past decades, the education system diverts attention to understanding multiple intelligences. Many have observed in the years that learners are composed of different exceptional individuals. Learning for others is fast, but some are weak and slows. Some are exciting, but others find it annoying and rather escape classes, preferably sitting all day listening to numbers and equations. Thus, this theory must translate into 
practices $^{(1)}$.

Mathematics is the science of expressing and studying the relationships between quantities and magnitudes as represented by numbers and symbols. Mathematics is the science of numbers and their operations, interrelations, combinations, generalizations and abstractions, space configurations, structure, measurement, transformation, and generalization ${ }^{(2)}$. Mathematics acquired through evidence helps students learn the subject effectively. There are four specific methods to learn Math, such as; explicit instruction, visual presentation, schema-based instruction, and peer interaction. Using these methods is useful for students struggling in Math ${ }^{(3)}$.

Thus, this study's formulation is based on the current trends, the multiple intelligence, but correctly applied tertiary students' numeral levels in Northern Iloilo Polytechnic State College (NIPSC). As a lone college in the northern part of Iloilo, NIPSC offers courses in education major in mathematics ${ }^{(4)}$. As future educators, it is essential to assess the levels and the way they learn Mathematics to become more effective and efficient educators and to expose in research because this is one of the requirements of DepEd for all teachers. Many DepEd teachers engaged in innovations to enhance teaching-learning but have never been tested for effectiveness ${ }^{(5)}$.

Furthermore, this research is planned to identify students' preferred intelligence and maximize their craft's identified skills. This study will also help develop the weakest skills thru remedial class and collaboration to linkages specifically to secondary schools in the district. The issues of NIPSC regarding the National College Aptitude Test (NCAT) are one of the concerns of this study, explicitly to students majoring in Mathematics. Thus, this study aimed to determine the level of multiple intelligences and their relationship to the Mathematics Performance of the first-year college students taking up a BSEd major in Mathematics in the four campuses of Northern Iloilo Polytechnic State College (NIPSC), $5^{\text {th }}$ District of Iloilo, Philippines.

\section{Background}

\subsection{Theory of Multiple Intelligence}

This study was anchored on the Theory of Multiple Intelligence (MI). Schools and culture focus most of their attention on linguistic and logical-mathematical intelligence. For many years, experts believed intelligence is all about the ability to solve problems ${ }^{(6)}$. The general notion of intelligence is IQ, but this is limited concepts ${ }^{(7)}$. Intelligence defined by Gardner as "the ability to solve problems, or to create products that are valued within one or more cultural"(6).

Thus, the concept of MI is the trend in early 2000-the theory of multiple intelligence recommended by Howard Gardner in1983. From then on, the understating of intelligence revolutionized. Human intelligence is composed of numerous types, such as;

1. verbal-linguistic intelligence,

2. mathematical-logical intelligence,

3. musical intelligence,

4. visual-spatial intelligence,

5. bodily-kinesthetic intelligence,

6. interpersonal intelligence,

7. intrapersonal intelligence,

8. naturalist intelligence,

9. and existential intelligence ${ }^{(8)}$.

Thus, the traditional way of running a school proposed a significant transformation in the theory of multiple intelligence. The theory suggested that learnings converted into more activities by integrating different activities from music to dance, games, arts, drama, poetry, and many more. This approach gained worldwide attention ${ }^{(7)}$. In the Philippines, both basic and tertiary education joined the bandwagon. All teachers are trained to equip with the necessary knowledge and skills to implement the current trend.

The theory is a guiding ideology in the US that profoundly impacts the education system and regulates teaching reform. Many schools claim to multiple intelligence schools. It was introduced at the end of the twentieth century in China, researches upsurge, but no claims published of the success of the approach in Chinese learners ${ }^{(9)}$. However, no studies showed evidence of the effectiveness of the theory ${ }^{(10)}$. 


\subsection{Multiple Intelligence: A Current Trend}

Using a multiple intelligence approach helps learners become part of society because it will showcase their abilities ${ }^{(11)}$. Science showed one preferred learning style has no benefit for students to understand and retain learning. Learning is a complex process, and thousands of variables affect knowledge; thus, teachers should reflect students' individuality to create effective lesson plans ${ }^{(12)}$.

Students controlled by different forms of intelligence almost possessed more than one kind of intelligence. Out of the various forms of intelligence, logical/mathematical, musical, and spatial were positively correlated with the IQ score. Also, learners with low IQ have different forms of intelligence. Thus, finding students' intelligence can help enhance their learning process ${ }^{(13)}$.

\subsection{Implementation of Multiple Intelligence in Tertiary Level}

Bright students tend to go to school longer compared to average learners. After basic education, they incline to go farther to college or even graduate programs. Thus, one of these criteria for above-average students is to go to the best university. Gardner's study to enhance higher education quality in the US is always linked to multiple intelligences. The additional human intelligence from 7 to 9 synthesized from ongoing studies his team conducted ${ }^{(14)}$. Thus, many countries worldwide also engaged in studies related to multiple intelligence to enhance higher education equality. Some amended the curriculum and embraced the best practices of the best universities in the US.

Students must have prior knowledge about their own MI and online activities implementing multiple intelligences inside the classroom. Instructors must be trained with the necessary skills and knowledge to implement MI effectively to e-learning ${ }^{(15)}$.

\subsection{Multiple Intelligence in Mathematics}

Mathematics is best taught in individualized instruction; however, this suggestion is often neglected. The subjects often followed a teacher-led approach by students doing individual activities and group reinforcement. The results revealed logical, spatial, existential, intrapersonal, and naturalist positively correlated with linguistic, bodily, and interpersonal in studying mathematical problem solving for $\mathrm{K}^{(16)}$. Furthermore, the study between emotional intelligence and teaching performance showed no correlation because students were focused on the passing the course ${ }^{(17)}$.

Teachers' role in mathematics education, aside from charts and other traditional instruction modalities, was to use words, pictures, gestures, phrases, rhythmic, and experiences to make learners understand the subject better ${ }^{(18)}$. Also, complex problem solving and intelligence showed significant and substantial correlations. Brain skills play critical parts in doing problemsolving ${ }^{(19)}$.

One of Gardner's nine multiple intelligence is the logical-mathematical intelligence about one's ability to solve and analyzed logical and mathematical operations. This process involved formal and informal reasoning. People who belong to these MI showed interest in math problems, strategy games, and rational explanations. Teachers organized activities that allow them to hold a collection, figure out different ways to answer a math problem, look for patterns in poetry, come up with a hypothesis and then prove it, work out logic puzzles, and count to $100-$ or 1,000 - by 2's, 3's, 4's, etc. ${ }^{(20)}$.

\section{Methods}

\subsection{Research Design}

This study utilized the descriptive-correlational design to identify the level of multiple intelligences and Mathematics performance as determinants of the Bachelor of Secondary Education major in Mathematics in the four campuses of Northern Iloilo Polytechnic State College.

\subsection{Locale and Respondents of the Study}

This study took place in the only tertiary institution in the northern part of Iloilo, the Northern Iloilo Polytechnic State College (NIPSC). Out of 7 campuses, Ajuy, Barotac Viejo, Batad, Concepcion, Lemery, Estancia (Main Campus), and Victorino Salcedo (Sara). Four of these schools are offering a Bachelor of Secondary Education (BSED) major in Mathematics.

Table 1 shows the number of respondents in the study from different campuses. 
Table 1. Total respondents from different Campuses

\begin{tabular}{ll}
\hline Campus & Number of Respondents \\
\hline Ajuy & 20 \\
Barotac Viejo & 14 \\
Concepcion & 12 \\
Main Campus (Estancia) & 20 \\
Total & 68 \\
\hline
\end{tabular}

This research was conducted last Academic Year 2015-2016. The total parameter was used as a sampling technique; thus, all students enrolled in Education major in Mathematics were considered participants.

\subsection{Research Instrument}

The tool employed in identifying the level of multiple intelligences used the questionnaire made by Dr. Terry Armstrong. The questionnaires serve as a measure of the MI of the respondents. The instrument has two parts. Part 1 is about the respondents' data, and part 2 is the measurement tools to describe the respondents' multiple intelligences. Likewise, the secondary data for Mathematics performance of the respondents for Academic Year 2015-2016 was also gathered to complete the BSEd major determinants in mathematics among the four campuses of NIPSC. The researcher-made questionnaire was pre-tested with a Cronbach Alpha of 0.746 . To measure the level of multiple intelligences was personally administered by the researcher on a oneshot survey. The instrument for the other determinants, which is the Mathematics performance, was likewise gathered utilizing the researcher-made guided questionnaire to supplement the necessary secondary data in the four campuses of NIPSC. ANOVA was used to measure the test of differences, and to test the relationship, Chi-square and Pearson $r$ were employed.

\section{Results and Discussion}

\subsection{Profile of the Respondents}

Table 2 shows the 68 respondents involved, 14 (20.59\%) were males, and 54 (79.41\%) were females.

Table 2. Profile of the Respondents

\begin{tabular}{lll}
\hline Campus & Frequency & Percentage \\
\hline Sex & & \\
Male & 14 & 20.59 \\
Female & 54 & 79.41 \\
\hline Total & 68 & 100.00 \\
\hline School campus & & \\
Ajuy & 20 & 29.41 \\
Barotac Viejo & 14 & 20.59 \\
Concepcion & 14 & 20.59 \\
Estancia & 20 & 29.41 \\
\hline Total & 68 & 100.00 \\
\hline High school graduated from & & \\
Inland barangay & 49 & 74.06 \\
Island barangay & 17 & 25.00 \\
Others & 2 & 2.94 \\
\hline Total & 68 & 100.00 \\
\hline
\end{tabular}

Table 2 manifests that females dominate the BSED-Math program in terms of numbers. The documents conform with the general observation that there are more female than male teachers in almost all schools, both private and public. However, there has been a growing number of males entering the teaching profession nowadays. Still, only a few males would desire to enroll in education courses. By school campus, Ajuy and Estancia Campus have both 20 (29.41\%) respondents, while Barotac Viejo and Concepcion have both 14 (20.59\%) respondents, respectively. The majority of the respondents, 49 (72.06\%), came from an inland barangay; 17 (25.00\%) graduated from an island barangay, and two (2.94\%) came from outside the fifth district of Iloilo. Also, the data show that the majority of the mathematics enrollees came from inland barangay high schools. 
The girls are more nervous than boys in learning mathematics at an early age. Furthermore, one predictor for math performance and math-related professions is attitude. But in general, gender always has different values, such as women usually work with people, but men work with things. Thus, the gender gap still connects in the selection of math-related careers ${ }^{(21)}$.

\subsection{Level of Multiple Intelligences of the Respondents}

Table 3 shows the level of MI of the respondents.

Table 3. Level of Multiple Intelligences of the Respondents

\begin{tabular}{llll}
\hline Category & Mean & SD & Interpretation \\
\hline 1. verbal-linguistic intelligence & 4.37 & 0.960 & Very High \\
2. mathematical-logical intelligence & 3.59 & 1.011 & High \\
3. visual-spatial intelligence & 4.13 & 0.913 & High \\
4. musical intelligence & 3.41 & 1.021 & High \\
5. bodily-kinesthetic intelligence & 4.21 & 0.998 & Very High \\
6. interpersonal intelligence & 4.09 & 0.973 & High \\
7. intrapersonal intelligence & 4.21 & 1.140 & Very High \\
8. naturalist intelligence & 3.85 & 1.296 & High \\
9. existential intelligence & 4.41 & 0.868 & Very High \\
\hline
\end{tabular}

Among the nine types of multiple intelligences, existentialists intelligence was dominant among respondents. The study revealed in Table 3, a very high level of existential knowledge of the respondents with (Mean=4.21; $\mathrm{SD}=0.868$ ). Most of the respondents studied in NIPSC because of the encouragement of their parents' expectations and personal goals. And they decide to finish the course and become successful mathematics teachers. Many of them have no interest in co-curricular activities. Existentialists intelligence is the ability to understand others based on values and intuitions ${ }^{(22)}$.

\subsection{Level of Mathematics Performance of the Respondents}

Table 4 shows the mathematics performance of the respondents.

Table 4. Mathematics Performance of the Respondents

\begin{tabular}{llll}
\hline Math Score & Frequency, $\mathrm{n}=68$ & Percentage $(\%)$ & Interpretation \\
\hline 14 and below & 19 & 27.94 & Failed \\
$15-19$ & 26 & 38.24 & Passed \\
$20-23$ & 15 & 22.06 & Passed \\
24 and above & 8 & 11.76 & Satisfactory \\
\hline
\end{tabular}

The study depicts the Mathematics performance in the college entrance examination of the respondents. The result shows that eight (11.76\%) obtained a score that falls between 24 and above, described to be "satisfactory." On the other hand, fifteen (22.06\%) got a score that falls between 20-23. Also, 26 (38.24\%) obtained a score that falls between 15-19, and they were both described as "passed." Results further revealed that the majority of the respondents earned a score below the median. The results showed that most of the respondents have poor preparation in mathematics during their basic education program. Collaboration among DepEd schools in the district is essential, provide remedial classes in Mathematics in the Senior High School program.

\subsection{Difference between Mathematics Performance and Campus}

Table 5 shows the difference between Mathematics performance and Campus

The study reveals the f-test results of the difference between Mathematics Performance and Campus. F-test results $\mathrm{f}$ (68), Fvalue of 11.985 , a p-value of $0.000, \mathrm{p}<0.05$, supports the decision to reject the null hypothesis and is interpreted as a significant difference. Ajuy campus marked the significant difference because it showed the lowest scores for Mathematics performance than the mean scores of Barotac Viejo campus being the highest, followed by the Concepcion campus as second highest Estancia the third when Mathematics performance is concerned. 
Table 5. Difference between Mathematics Performance and Campus

\begin{tabular}{lcccccc}
\hline Sources of Variation & Mean & SD & F-value & p-value & Decision on Ho & Interpretation \\
\hline Mathematics & & & & & & \\
Ajuy & 15.20 & 0.322 & & & & \\
Barotac Viejo & 21.00 & 1.961 & 11.985 & $0.000^{* *}$ & Reject Ho & Significant \\
Concepcion & 20.57 & 3.251 & & & & \\
Estancia & 18.75 & 3.754 & & & & \\
\hline
\end{tabular}

Note: Significant $\left({ }^{*}\right)$ if -value $<0.05$ Level of Significance

\subsection{Test of Relationship Between the Profile (sex) and Level of Multiple Intelligences (MI) of the Respondents}

Table 6 presents the test o relations between Sex and Level of MI of the respondents

Table 6. Relationship between the profile (sex) and Level of Multiple Intelligences (MI)

\begin{tabular}{lllll}
\hline Profile/Indicator & Chi-squared & p-value & Decision on Ho & Interpretation \\
\hline Linguistic & 20.153 & 0.305 & Do not Reject Ho & Not Significant \\
Mathematical & 24.428 & 0.273 & Do not Reject Ho & Not Significant \\
Musical & 19.375 & 0.679 & Do not Reject Ho & Not Significant \\
Spatial & 18.865 & 0.594 & Do not Reject Ho & Not Significant \\
Kinesthetic & 17.132 & 0.703 & Do not Reject Ho & Not Significant \\
Interpersonal & 29.772 & $0.028^{*}$ & Reject Ho & Significant \\
Intrapersonal & 22.807 & 0.246 & Do not Reject Ho & Not Significant \\
Naturalist & 21.108 & 0.514 & Do not Reject Ho & Not Significant \\
Existentialist & 20.962 & 0.180 & Do not Reject Ho & Not Significant \\
\hline
\end{tabular}

Note: Significant $\left(^{*}\right)$ if p-value $<0.05$ Level of Significance

Not Significant (NS) if p-value $>0.05$ Level of Significance

The result revealed that as to sex and interpersonal intelligence, a significant relationship is indicated by the p-value of 0.028 . Therefore, the null hypothesis is rejected. On the other hand, between sex and all other multiple intelligences, no significant relationship was noted.

\subsection{Relationship Between Profile and Mathematics Performance}

Table 7 shows the relationship between profile and Mathematics performance.

Table 7. Relationship between Profile and Mathematics Performance

\begin{tabular}{lllll}
\hline Profile vs. Math & Chi-squared & p-value & Decision on Ho & Interpretation \\
\hline Sex & 23.044 & 0.613 & Do not Reject Ho & Not Significant \\
Campus & 94.229 & 0.149 & Do not Reject Ho & Not Significant \\
High school graduated from & 76.682 & $0.023^{*}$ & Reject Ho & Significant \\
\hline
\end{tabular}

Note: Significant $(*)$ if p-value $<0.05$ Level of Significance

Not Significant (NS) if p-value $>0.05$ Level of Significance

The study discloses the relationships between the profile and Mathematics performance of the respondents. A significant correlation is noted between the high school graduated from and mathematics performance, as indicated in the p-value of 0.023 , less than the 0.05 level of significance, rejecting the null hypothesis. The results imply that a particular high school may produce graduates who perform better in mathematics. Alternatively, one study conducted found out that students' college academic performance is high when their Mathematics admission test score is also high ${ }^{(23)}$. 


\subsection{Relationship between Mathematics Performance and Multiple Intelligences}

As to the relationship between the Mathematics Performance (MP) and Multiple Intelligences (MI) of the respondents, the only significant relationship noted is between mathematics performance and the respondents' level of linguistic intelligence. The p-value of 0.025 , which is less than the 0.05 level of significance, prompts the decision to reject the null hypothesis. This means that the respondents possess such linguistic intelligence that can motivate them to read, analyze, and comprehend verbal instructions in solving Mathematics problems, whether expressed in symbols or words.

\section{Conclusions}

Every teacher's success in encouraging learners to excel in the class depends on the utilization of MI. Catering all MI inside the class encourages activity participation among learners. Specifically, at tertiary levels, learning is more advanced and sophisticated. Being a future teacher majoring in Mathematics, learning requires more dedication and perseverance. Thus, this study was formulated to help understand the learning of BSEd Mathematics in NIPSC. The results showed more females enrolled in the programs than males in the academic year 2015-2016. Most of these students were from different barangays in northern Iloilo. Out of the $9 \mathrm{MI}$, most of the students possessed existentialist intelligence because they wanted to become teachers in the future. However, the majority of these 68 respondents failed the entrance examination. But out of four campuses, Barotac Viejo Campus students have a higher performance in Mathematic class. But no significant difference between sex and MI.

Furthermore, the results also exposed that if students excelled in Mathematics in high school, they were too good in college. Also, most of the respondents possessed linguistic intelligence. During problem-solving activities, most of them can read, analyze, and comprehend verbal instructions.

Based on the study's findings, a proposed action plan for remedial/review class among senior high school students required. They should also conduct training programs among basic education teachers, explicitly in junior high school (JHS) and senior high school (SHS). Learnings acquire those these stages are critical to have excellent students enrolled in BSEd major in Mathematics. If these will not be correct, results in professional licenser will also affect the school.

\section{References}

1) Bumen NT. The Benefits and Problems of Multiple-Intelligence-Based Instruction: A Case Study in Turkey. International Journal of Educational Reform. 2007;16(1):38-53.

2) Dewolf M, Bassok M, Holyoak KJ. Numbers as Mathematical Models: Modeling Relations and Magnitudes with Fractions and Decimals. Mathematical Cognition and Learning. 2017;p. 141-163. Available from: https://doi.org/10.1016/B978-0-12-805086-6.00007-2.

3) Evidence-based Math Instruction: What You Need to Know. . Available from: https://www.understood.org/en/school-learning/for-educators/teachingstrategies/evidence-based-math-instruction-for-struggling-students.

4) Tupas FP, Matsuura T. Moving Forward in STEM Education, Challenges, and Innovations in Senior High School in the Philippines: The Case of Northern Iloilo Polytechnic State College. Jurnal Pendedika IPA Indonesian. 2019;8(3):406-416. Available from: 10.15294/jpii.v8i3.19707.

5) Tupas FP. Close Mentoring Approach: Enhancing Action Research Skills and Knowledge of Science and Mathematics Teachers. Journal of Educational and Social Research. 2019;9(3):107-116. Available from: https://dx.doi.org/10.2478/jesr-2019-0028.

6) Howard Gardner and the Theory of Multiple Intelligence. . Available from: https://exploringyourmind.com/howard-gardner-theory-multipleintelligences.

7) Multiple Intelligence. . Available from: https://www.institute4learning.com/resources/articles/multiple-intelligences.

8) Multiple Intelligence, What Does the Research Say? . . Available from: https://www.edutopia.org/multiple-intelligences-research.

9) Wang H. Research on Multiple Intelligence Theory and Its Enlightenment to Higher Education. Research on Modern Education. 2017;3. Available from: 10.24104/r,he/2017.03.02010.

10) The Illusory Theory of Multiple Intelligence. . Available from: https://www.psychologytoday.com/us/blog/unique-everybody-else/201311/the-illusorytheory-multiple-intelligences.

11) Harman MJ, Kordinak ST, Bruce AJ. Multiple Intelligences: Current Trends in Assessment. Journal on Educational Psychology. 2009;2(3):9-13.

12) The Myth of Multiple Intelligence: Its Impact on E-learning. . Available from: https://www.smartdatacollective.com/myth-multiple-intelligences-impactelearning/.

13) Singh Y, Makharia A, Sharma A, Agrawal K, Varma G, Yadav T. A study on different forms of intelligence in Indian school-going children. Industrial Psychiatry Journal. 2017;26(1):71-76. Available from: https://dx.doi.org/10.4103/ipj.ipj_61_16.

14) Multiple intelligence. . Available from: https://www.psychologytoday.com/us/blog/how-do-life/201604/multiple-intelligence-higher-education-reformand-ethics.

15) Tyler CE, Loventhal G. Can Multiple Intelligences Enhance Learning for Higher Education On-Line Instruction? ELeader. Vietnam. 2011.

16) Rahbarnia F, Hamedian S, Radmehr F. A Study on the Relationship Between Multiple Intelligences and Mathematical Problem Solving Based on Revised Bloom Taxonomy. Journal of Interdisciplinary Mathematics. 2012;17(2):109-134.

17) Cornejar MN. Student Teaching Performance and Emotional Intelligence of Bachelor of Secondary Education Students of Southern Iloilo Polytechnic College-WVCST Miagao Campus: Baseline Data for Career Counseling Program. 2014.

18) karamikabir N. Gardner's Multiple Intelligence and Mathematics Education. Procedia - Social and Behavioral Sciences. 2012;31:778-781. Available from: https://dx.doi.org/10.1016/j.sbspro.2011.12.140. 
19) Stadler M, Becker N, Gödker M, Leutner D, Greiff S. Complex problem solving and intelligence: A meta-analysis. Intelligence. 2015;53:92-101. Available from: https://dx.doi.org/10.1016/j.intell.2015.09.005.

20) How to Analyze Problems Using Logical-Mathematical Intelligence?. . Available from: https://www.thoughtco.com/logical-mathematical-intelligenceprofile-8094.

21) Current Research on the Gender Difference in Math. 2018. Available from: https://www.nctm.org/Publications/Teaching-Children-Mathematics/Blog/ Current-Research-on-Gender-Differences-in-Math/.

22) Mcoog IJ. The Existential Learners. The Clearing House. 2010;83:126-128. Available from: 10.1080/00098651003774828.

23) Pascua JB, Navalta JD, Cruz DL, Valderama LM, S J. College Academic Performance of Teacher Education Students in a State University of Northern Philippines. JPAIR Multidisciplinary Journal. 2015;9(1):177-184. 